Article

\title{
Clostridium difficile Infection Epidemiology over a Period of 8 Years-A Single Centre Study
}

\author{
Nicoleta Negrut ${ }^{1}$, Delia Carmen Nistor-Cseppento ${ }^{1}$, Shamim Ahmad Khan ${ }^{2}$, Carmen Pantis ${ }^{3}$, \\ Teodor Andrei Maghiar ${ }^{3}$, Octavian Maghiar ${ }^{3}$, Selim Aleya ${ }^{4}$, Marius Rus ${ }^{5}$, Delia Mirela Tit ${ }^{6}{ }^{\circ}$, \\ Lotfi Aleya ${ }^{7}$, Abbas Rahdar ${ }^{8}$ and Simona Bungau ${ }^{6, *(D)}$ \\ 1 Department of Psycho-Neuroscience and Recovery, Faculty of Medicine and Pharmacy, University of \\ Oradea, 410073 Oradea, Romania; Inm_n10@yahoo.com (N.N.); delia_cseppento@yahoo.com (D.C.N.-C.) \\ 2 Faculty of Medicine and Pharmacy, University of Oradea, 410073 Oradea, Romania; doc5984@gmail.com \\ 3 Department of Surgical Disciplines, Faculty of Medicine and Pharmacy, University of Oradea, 410073 Oradea, \\ Romania; pantisc@yahoo.com (C.P.); teodormaghiar@yahoo.com (T.A.M.); octimaghiar@yahoo.com (O.M.) \\ 4 Faculty of Medicine, Université de Franche-Comté, 25000 Besançon, France; selim.aleya@sfr.fr \\ 5 Department of Medical Disciplines, Faculty of Medicine and Pharmacy, University of Oradea, 410073 \\ Oradea, Romania; rusmariusr@yahoo.com \\ 6 Department of Pharmacy, Faculty of Medicine and Pharmacy, University of Oradea, 410028 Oradea, \\ Romania; mirela_tit@yahoo.com \\ 7 Université de Franche-Comté, Chrono-environment CNRS 6249, 25000 Besançon, France; \\ lotfi.aleya@univ-fcomte.fr \\ 8 Department of Physics, University of Zabol, Zabol 98613-35856, Iran; a.rahdarnanophysics@gmail.com \\ * Correspondence: sbungau@uoradea.ro or simonabungau@gmail.com; Tel.: +40-726-776-588
}

Received: 14 May 2020; Accepted: 20 May 2020; Published: 29 May 2020

\begin{abstract}
Clostridium difficile infection (CDI) is the most common infectious disease related to antibiotic-associated diarrhoea and is a current leading cause of morbidity/mortality, with substantial consequences for healthcare services and overall public health. Thus, we performed a retrospective epidemiological study of CDI for a long period (8 years), in an infectious hospital located in north-western Romania, which serves an entire county of the country (617,827 inhabitants). From 2011 to 2018,877 patients were diagnosed with CDI; the mean incidence of this disease was 2.76 cases/10,000 patient-days, with an increasing trend in the annual incidence until 2016, at which point there was a decrease. The most commonly afflicted were patients in the 75-84 age group, observed in winter and spring. The results show that the antibiotics were administered in $679(77.42 \%)$ subjects, within the last 3 months before CDI, statistically significant more than proton-pump inhibitors (PPIs)-128 $(14.60 \%)$ and antidepressant medications-60 (6.84\%), which were administered during the same period $(p<0.001)$. No medication was reported in $10(6.84 \%)$ cases of CDI, in the last 3 months of the study. The fatality rate attained $4.1 \%$, tripling in 2018 vs. 2011 . CDI became a significant public health conundrum that can, nevertheless, be combatted through a judicious use of antibiotics.
\end{abstract}

Keywords: Clostridium difficile infection; epidemiology; proton-pump inhibitors; antidepressants; Romania

\section{Introduction}

Clostridium difficile (CD) is omnipresent in the environment; it is also considered to be a greatly important bacterium in diarrhoea-associated disease, for both different animal species and human. The incidence and the severity of CD infection (CDI) have significantly increased worldwide during the last two decades [1]. Often fatal, it can aggravate already existing pathologies and is responsible for generating outbreaks of nosocomial infections [2,3]. It can prolong hospitalization time and thus 
increases expenses and creates a vicious circle in which patients are exposed to healthcare services for increased periods, opening the opportunity for exposure to other multidrug-resistant pathogens [4].

As the most encountered cause of infections connected to the healthcare field, CD is a major concern for the medical network $[5,6]$. Although there are important actions to prevent and decrease the occurrence of CDI in hospitals, there still are serious effects, both clinical and economic. Several centers have implemented associated actions of various composition, manifestation and efficiency. Incomplete information about the effectiveness of existing treatments/interventions and the spread of this pathology makes it difficult to prevent healthcare-associated CDI (HA-CDI). [7]. Therefore, health approaches to CDI prevention and reduction should be reconsidered. In order to obtain better care and prevention on a large scale, programs and efficient interventions, with scalable and sustainable impact, need to be implemented in healthcare systems. All public health actions have to consider sustainability as well as the development of strategies for CDI from the individual disease management to a more consistent global medical approach [8]. In order to restrain the rates of CDI and decrease morbidity, it is necessary to approach $C D$ as a global health issue and to raise consciousness of its impact [9].

Also, the incidence of HA-CDI is a relevant qualitative indicator in terms of the healthcare system implemented both in each hospital and at the national level; it reflects the quality of antimicrobial administration as well as infection prevention [10].

In Romania, the widespread use of antibiotics [10-12], justified or not, and often with unrestricted access to them, has generated an upward trend in CDI. The use of antibiotics is responsible for the alteration of human gut microbiota (HGM), leading to dysbiosis [13]. Once the commensal microorganisms are destroyed, their place can be occupied by pathogens. $\mathrm{CD}$, an obligate anaerobic and spore-forming bacterium, is one of the most feared microorganisms likely to colonize the human gastrointestinal tract under such conditions, causing antibiotic-associated diarrhoea (AAD) along with pseudomembranous colitis (PMC). CD strains can be toxigenic (carrying toxin genes) and non-toxigenic (toxin genes are absent), both having the ability to colonize human and animal intestines. Spores can survive for a long term in the environment, being present in soil, water, and feces, and in healthcare settings [14]. In advantageous conditions, and inside the human host, they will germinate to a vegetative form responsible for toxin production. Enterotoxin A and cytotoxin B are responsible for inflammation, necrosis and increased vascular permeability at the host epithelial cell level, in the case of human colonization with toxigenic strains of CD. Another toxin (known as the binary toxin) has an unclear role in the disease's pathophysiology, usually being related to severe cases [15].

Beta-lactam antibiotics, including penicillin, are a class of drugs classified as frequently CDI-associated [16], but antibiotics are not only culprits to cause dysbiosis. Other risk factors predispose to CDI, such as gastric acid suppressants, antidepressants, immunocompromised hosts, gastrointestinal surgery, prolonged hospitalization and severe underlying conditions, such as acute lymphoblastic leukaemia with gastrointestinal involvement, which is the most frequent form of cancer in children, or gastrointestinal tract malignancy [17-19].

CDI has become a major public health problem due to the combination of several factors, such as asymptomatic colonization, the increased resistance of the spores in the environment and, especially in hospital environments, the emergence of hypervirulent strains. These strains synthesize binary toxins which determination is constrained by a lack of appropriate infrastructure and financial means [20]. Asymptomatic colonization is present in young children, medical staff and in the first week after cessation of correct etiological treatment conducted in symptomatic patients [21].

Regarding the increased incidence of CDI, even among the population considered to be at low risk to become infected and also to monitor the incidence and to establish the population at risk, this study aimed to present long-term epidemiologic data correlated with the evolution of CDI incidence, and the way in which the marked increase in antibiotic consumption influences it. 


\section{Materials and Methods}

\subsection{Protocol}

An 8-year retrospective study from January 1st, 2011, to December 31, 2018, was conducted in the Department of Infectious Diseases at Oradea Municipal Hospital "Gavril Curteanu”, Oradea, Romania, which provides medical services to the population of the entire Bihor county; according to the Romanian National Institute of Statistics (NIS), this county has a population of 617,827 (2018), 51\% living in urban areas [22]. All patients admitted with diarrhoea were tested for CDI. The demographic and epidemiologic data, past medical history (PMH), as well as the clinical features of the positive cases, were analysed. The following pathologies were registered: cardiovascular disease (CVD), diabetes mellitus (DM), inflammatory bowel disease (IBD), neoplasm (N), chronic kidney disease (CKD), hepatic cirrhosis (HC), chronic respiratory diseases (CRD), psychiatric diseases (PD), and past surgery history (PSH). Patients with no associated diseases nor presence in medical services were included in the category community acquired (CA). Diagnosis of CDI, and patient admission to the hospital during the first episode of CDI were criteria for being included in the study. Patients with AAD, but with $\mathrm{CD}$ toxins $\mathrm{A} / \mathrm{B}$ binary negative, and those with recurrent $\mathrm{CDI}$ within the 3 months following the first episode were excluded.

HA-CDIs were considered to be cases with onset in a healthcare unit declared within a minimum of 48 hours of admission, or within the first 4 weeks following discharge. Community-associated CDI (CA-CDI) were considered patients with onset of symptomatology during the first 48 hours after admission to a healthcare service, or the case of a patient having no presence in a healthcare service within the last 3 months.

Patients whose onset was between 4 and 12 weeks after discharge from a medical unit were classified as having an unknown origin of CDI (UO-CDI). The classification was made according to the European Society of Clinical Microbiology and Infectious Diseases [23].

\subsection{Ethical Statement}

All participants in the study signed an informed consent form at the hospital upon admission. The study was approved by the Ethics Commission of the Oradea Municipal Hospital "Gavril Curteanu", Oradea, Romania (no. 1026/12 September 2018) and conforms to the World Medical Association Code of Ethics (Declaration of Helsinki, 1967). The manuscript is in line with the Recommendations for the Conduct, Reporting, Editing and Publication of Scholarly Work in Medical Journals and aim for the inclusion of representative human populations (sex, age and ethnicity) as per those recommendations.

\subsection{Diagnosis of CDI}

The cases were checked for toxigenic $C D$ in all patients with diarrhoea ( $\geq 3$ unformed stools over 24-hour periods) prior to etiological treatment. Unformed stool samples were tested for the presence of free faecal toxins A and/or B using chromatographic immunoassay CerTest CD GDH+Toxin A+B, (CerTest Biotec, Spain) prior CDI treatment. Sensitivity for toxin A was $96.6 \%$ ( $95 \%$ confidence interval CI, $92.2 \%$ to $99.9 \%$ ), for toxin B of $100 \%$ (95\% CI, $92.2 \%$ to $99.9 \%$ ), specificity for toxin A was $100 \%$ ( $95 \%$ CI, $96.2 \%$ to $100 \%$ ), for toxin B of $98.9 \%$ (95\% CI, $94 \%$ to $100 \%$ ) [24].

The cases suspicion of CDI, negative at the previous determination, without another proven aetiology, were checked by Cepheid Xpert CD BT Assay (Cepheid, Sweden), utilizing real-time polymerase chain reaction. The test identifies hypervirulent strains of $C D$, producing binary toxin, by identifying $\mathrm{CD}$ toxin gene $\mathrm{B}(\mathrm{tcdB})$, binary toxin gene $(\mathrm{cdt})$, and a deletion of a nucleotide at position 117 of the tcdC accessory gene from patients' stool. The sensitivity of the test for toxigenic CD was $93.39 \%$ and the specificity $94.02 \%$, respectively [25].

For detection, 1-2 $\mathrm{g}$ of freshly emitted feces or 1-2 $\mathrm{mL}$ of liquid feces were collected in a sterile container, with no preservative added. The sample was transported to the laboratory as quickly as possible and analysed within a maximum of two hours. The results were expressed qualitatively. 


\subsection{Statistical Analysis}

The Software SPSS (Statistical Package for the Social Sciences), version 26, was used for statistical analysis and graphical representation. Chi-square test and Mann-Whitney U statistics for two independent variables were used to calculate the $p$-value. A $p$-value of less than 0.05 indicates statistical significance.

\section{Results}

Over the 8 years of study, 4354 patients, both children and adults, were diagnosed with acute gastroenteritis (AE), and 877 with CDI. The mean incidence density for the eight-year period was 2.76 cases per 10,000 patient-days. The mean CDI prevalence was $20.14 \%$, with annual variation from $7.65 \%$ to $41.45 \%$ (Figure 1). Over the 8 years of study, 4354 patients, both children and adults, were diagnosed with $\mathrm{AE}$, and 877 with $\mathrm{CDI}$. The incidence rate was 2.76 cases per 10,000 patient-days. The mean infection rate was $20.14 \%$, with annual variation from $7.65 \%$ to $41.45 \%$ (Figure 2). The frequency of CDI cases increased, starting in 2011 and reaching its maximum in 2016. The incidence density of CDI cases is depicted in Figure 2. The distribution of confirmed CDI cases by age and gender is presented in Figure 3.

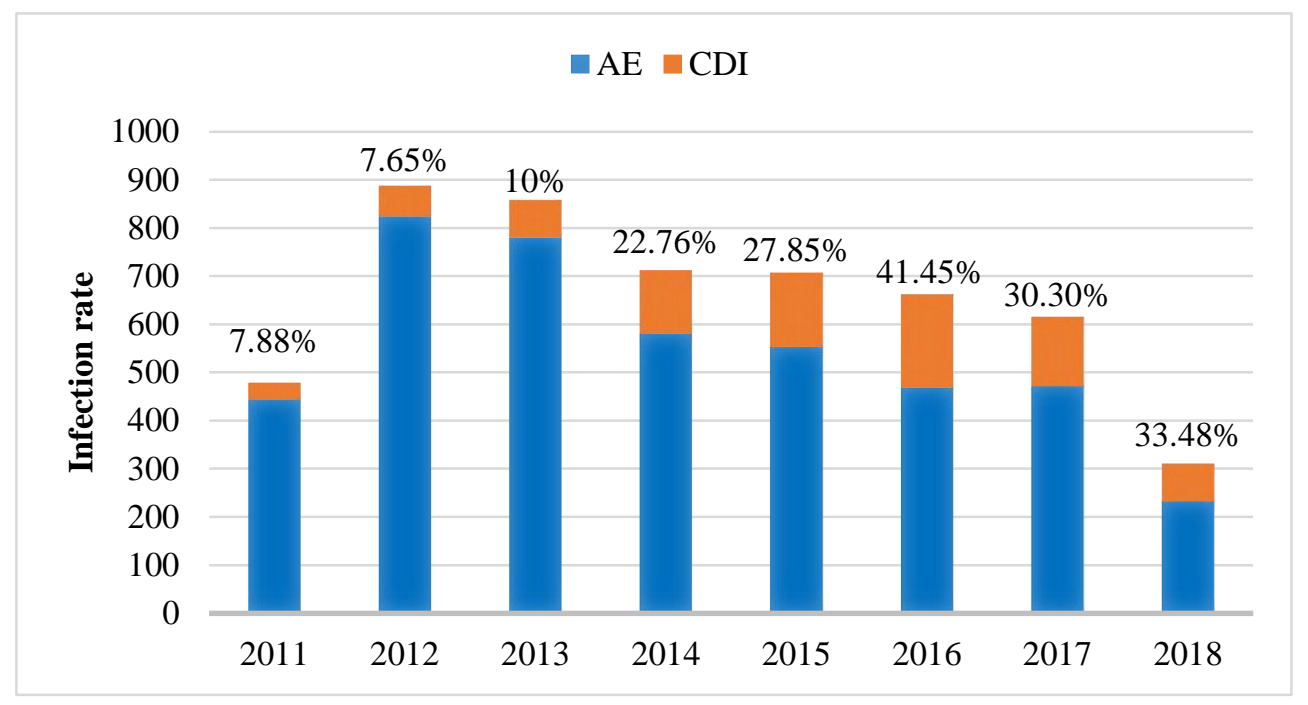

Figure 1. Infection rate of $\mathrm{CDI}$ according to year. AE-acute gastroenteritis; CDI-Clostridium difficile infection.

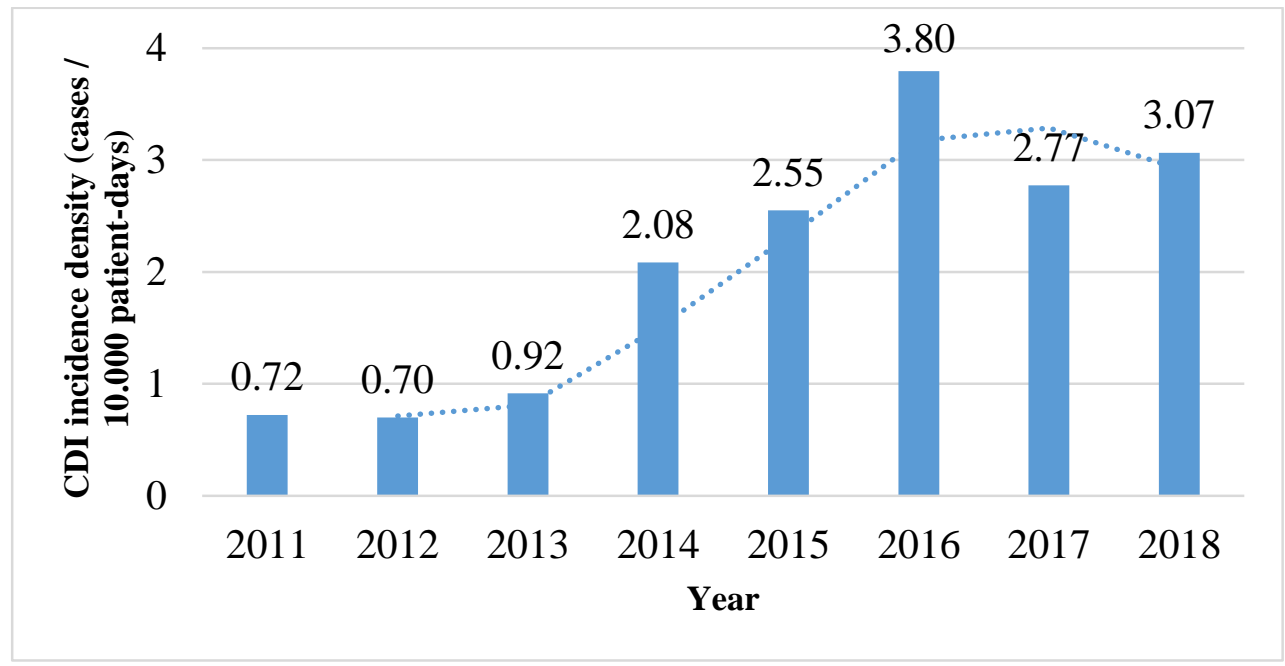

Figure 2. Incidence density of CDI according to year. 


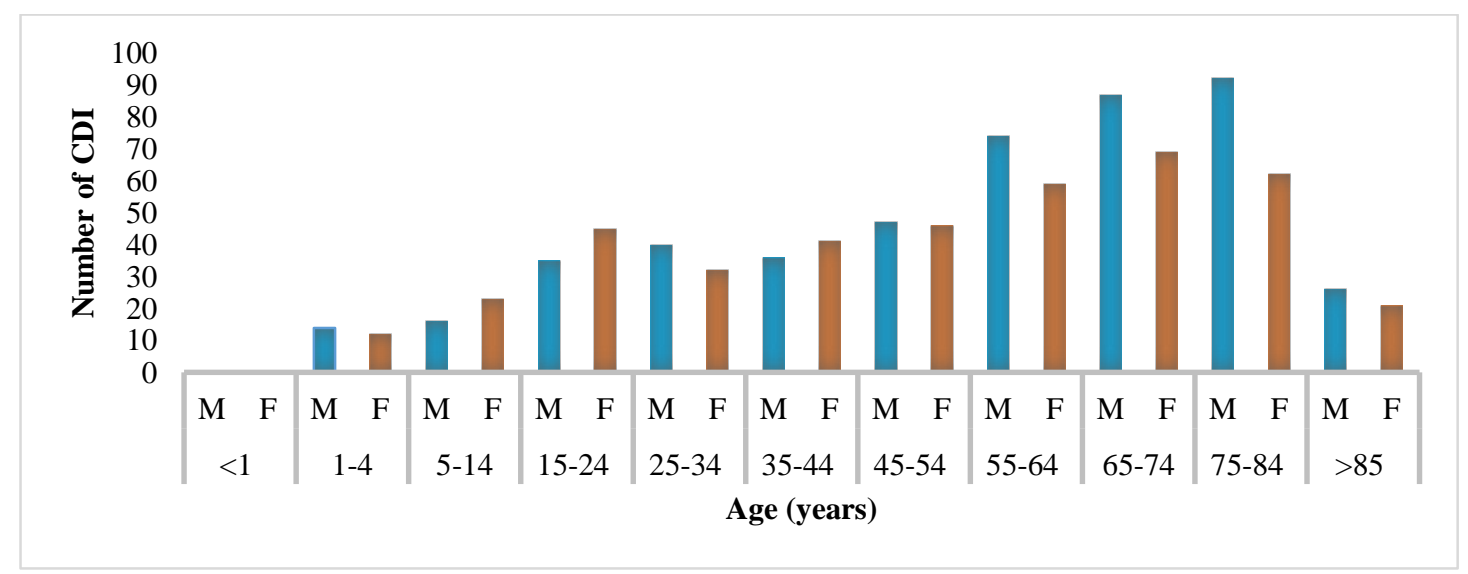

Figure 3. Distribution of confirmed CDI cases by age and gender: $\mathrm{M}-$ male; F-female.

The incidence of CDI according to residence was higher in patients from rural areas $(452,51.54 \%)$, with an urban to rural ratio of 1:1.06, and no statistical significance, $p=0.36$ (Figure 4). Statistically, CDI cases were significantly more frequent in the winter-spring season than in the summer-autumn period (475 vs. 402, $p=0.013$ ) (Figure 5).

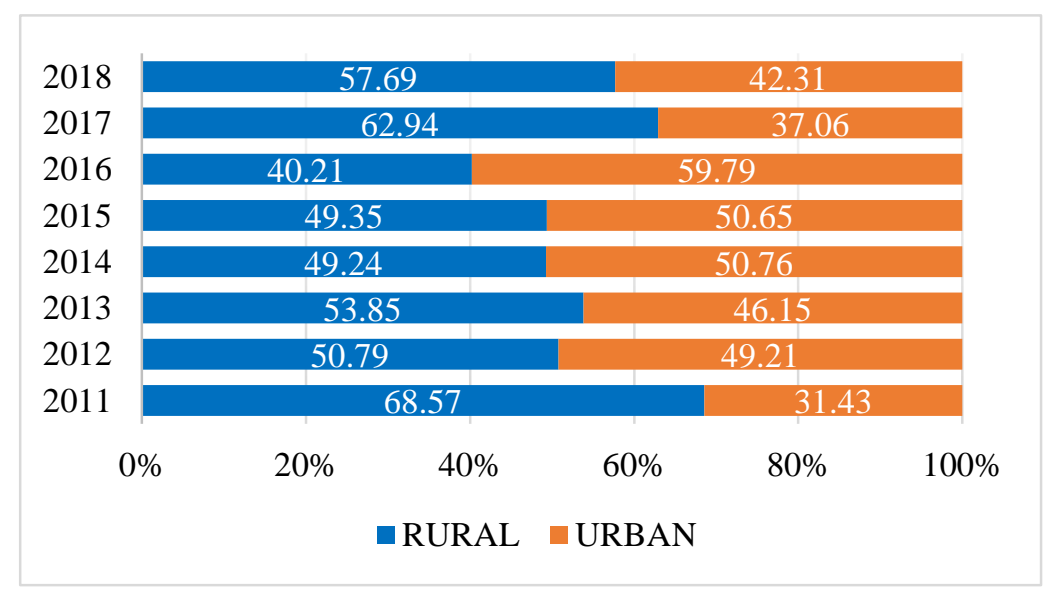

Figure 4. Distribution of confirmed CDI cases by residence.

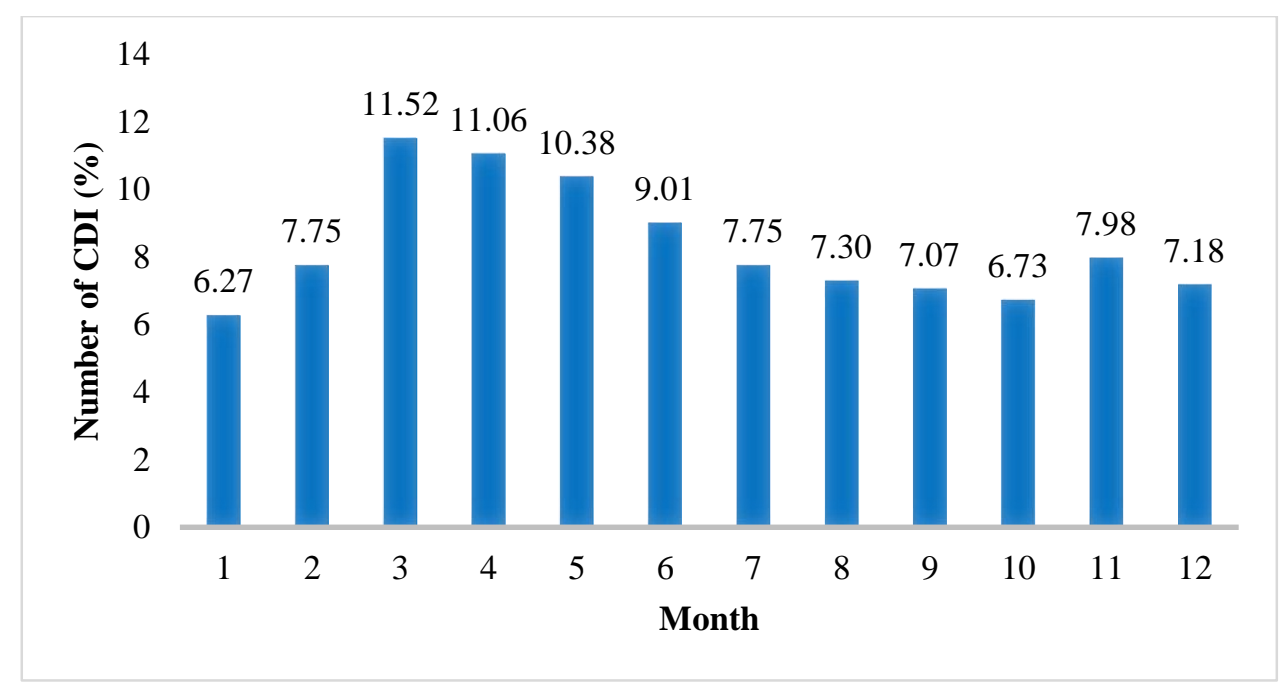

Figure 5. Distribution of confirmed CDI cases by month. 
It was revealed that antibiotics (ATBT) had been administered in 679 (77.42\%) cases within the last 3 months before CDI, statistically significant more than proton-pump inhibitors (PPIs) - 128 (14.60\%) and antidepressant medications (AD) —60 (6.84\%) administered in the same period $(p<0.001)$. In 10 $(6.84 \%)$ cases of CDI, no medication was reported (NM) in the last 3 months (Figure 6 ).

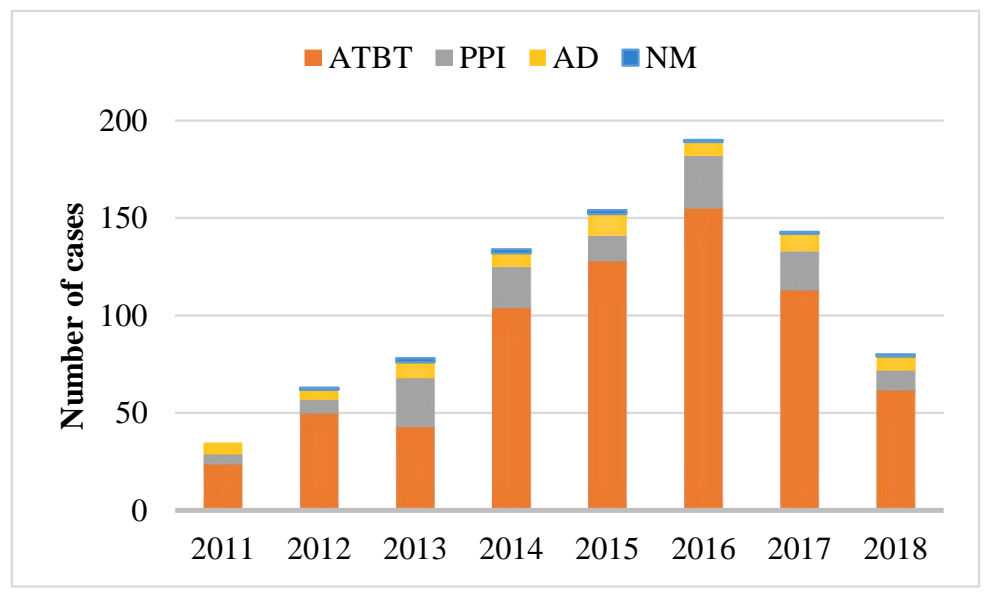

Figure 6. Drug use associated with CDI: ATBT-antibiotics; PPI-proton-pump inhibitors; AD—antidepressant medications; NM-no medication.

During the 8 years of the study, almost half of the cases (378/43\%) were recorded in association with cephalosporins. The lowest values were recorded in cases previously treated with macrolides $(27 / 3 \%)$ and antitubercular agents (27/3\%). Fluoroquinolones were found in association with $193(22 \%)$ cases with CDI, aminopenicillins in 167 (19\%) cases, and rifaximin in 88 (10\%).

During the first 4 years monitored, treatment with cephalosporins and fluoroquinolones tended to rise, but then decreased during the last 4 years, while the other antibiotics showed a positive increasing trend (Figure 7).

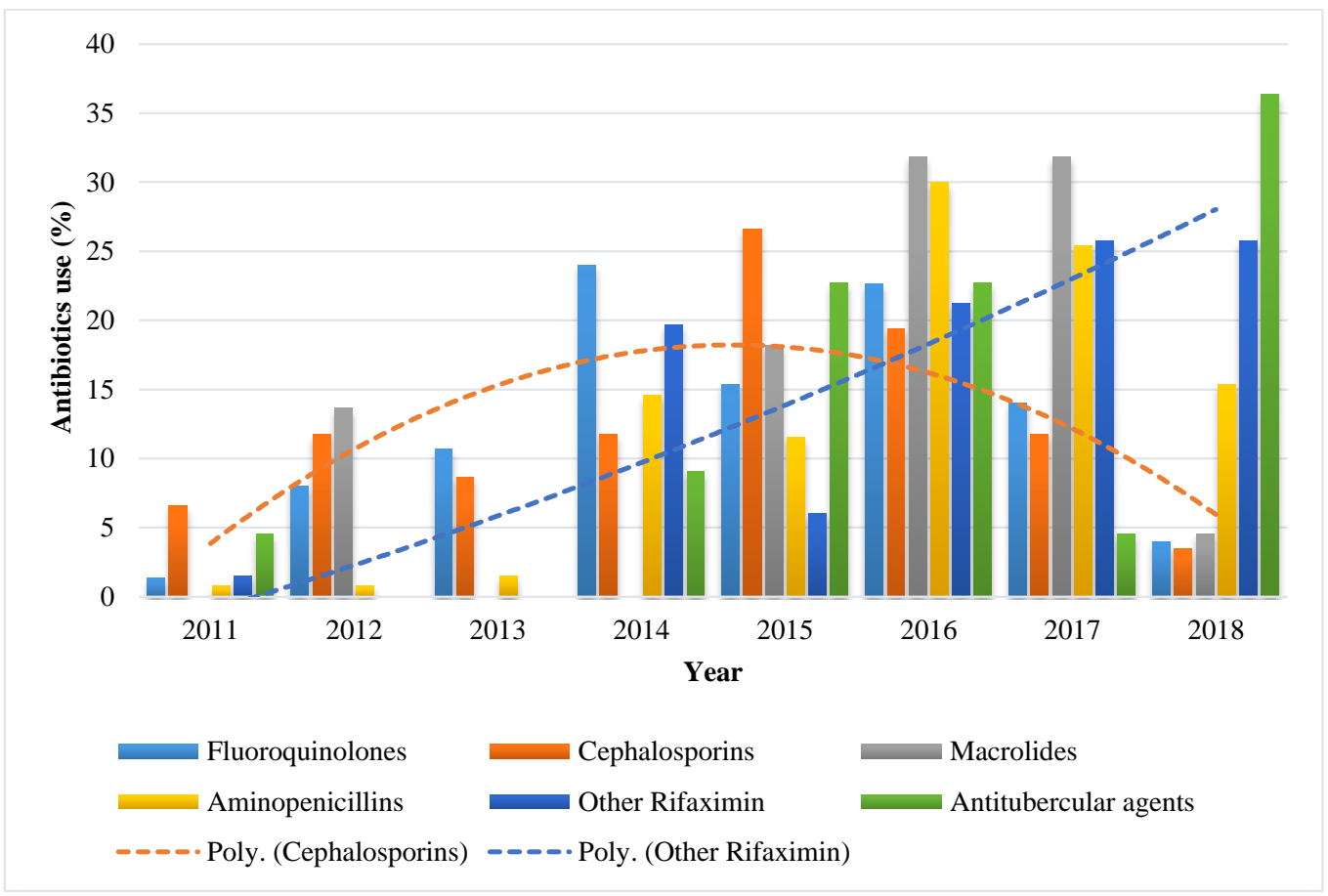

Figure 7. Distribution of cases with CDI according to the trend of antibiotic use. 
Regarding the recent hospitalization of CDI patients, 498 (56.78\%) were HA-CDI, statistically significantly higher than $251(28.62 \%)$ cases of CA-CDI, and $128(14.60 \%)$ cases of UO-CDI $(p<0.001)$ (Figure 8). Past surgery history (PSH), cardiovascular diseases (CVD), and psychiatric diseases (PD) were most commonly associated with CDI (Figure 9).

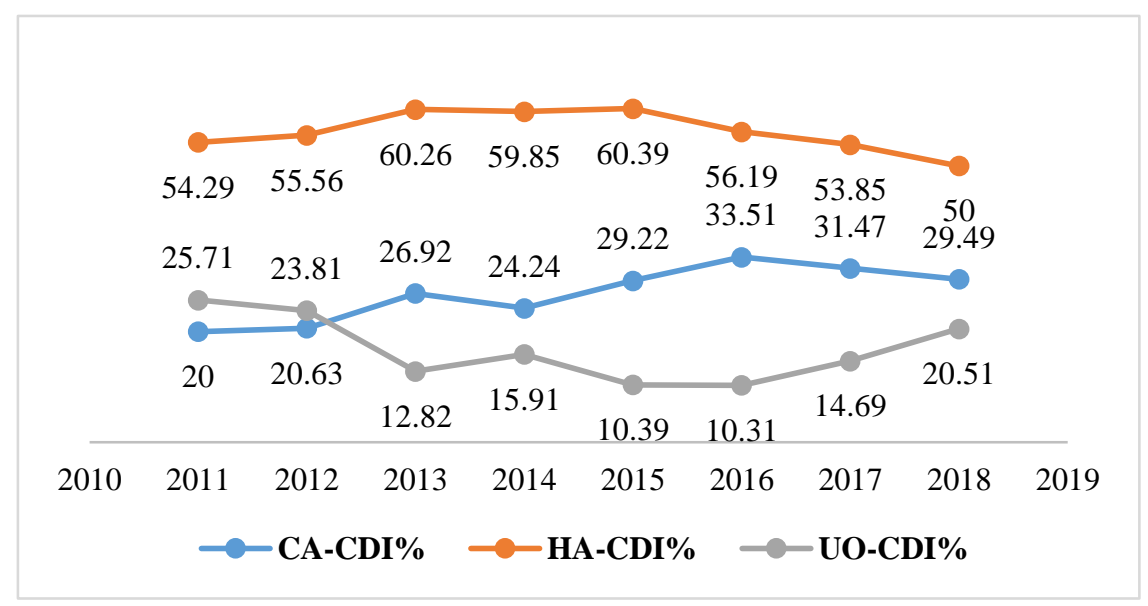

Figure 8. Rates of community-associated CDI (CA-CDI), healthcare-associated CDI (HA-CDI), and unknown origin CDI (UO-CDI) by years.

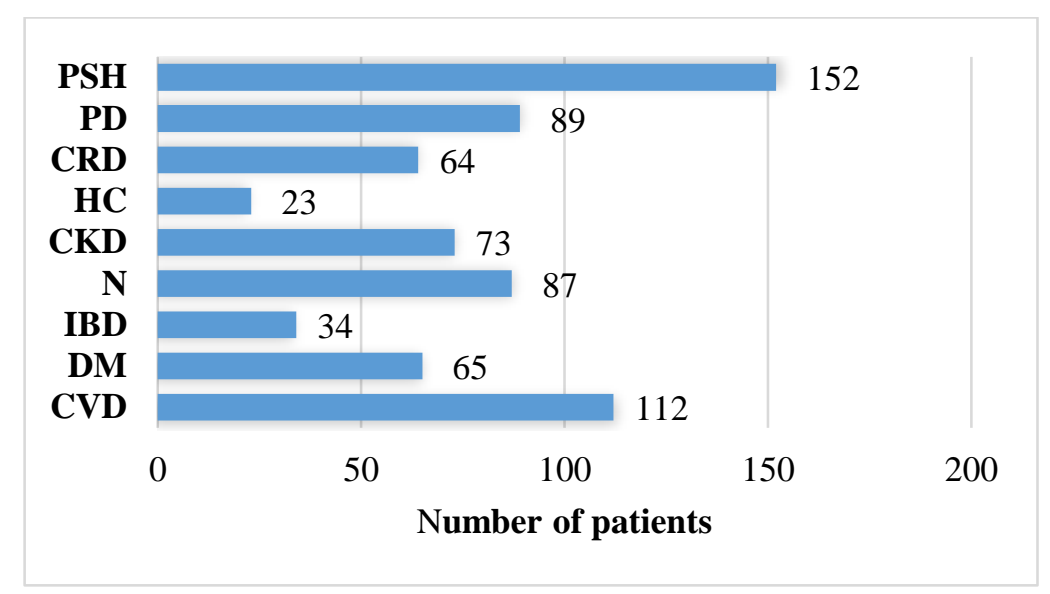

Figure 9. Prevalence of HA-CDI according to PMH: HA-CDI-Healthcare-associated-Clostridium difficile infection; $\mathrm{PMH}$-past medical history; $\mathrm{PSH}$-past surgery history; PD—psychiatric diseases; $\mathrm{CRD}$ — chronic respiratory diseases; $\mathrm{HC}$ - hepatic cirrhosis; $\mathrm{CKD}$ —chronic kidney diseases; $\mathrm{N}$-neoplasm; IBD—inflammatory bowel disease; DM—diabetes mellitus; CVD—cardiovascular diseases.

A CDI proportional mortality rate of $72 \%$ was reported for the total numbers of deaths occurring due to digestive infectious diseases, with a case fatality rate of 4.1\% (Figure 10). From 2011 to 2018, the case fatality rate tripled from $2.86 \%$ to $8.97 \%$. Females were more affected than males, but the difference was not statistically significant $(p=0.182)$. The mean age at which death from CDI occurred was $73.97 \pm 8.91$ years (range 60-89 years). Death from CDI occurred, on average, at $7.27 \pm 5.99$ days, (range 1-19 days) after hospital admission. 


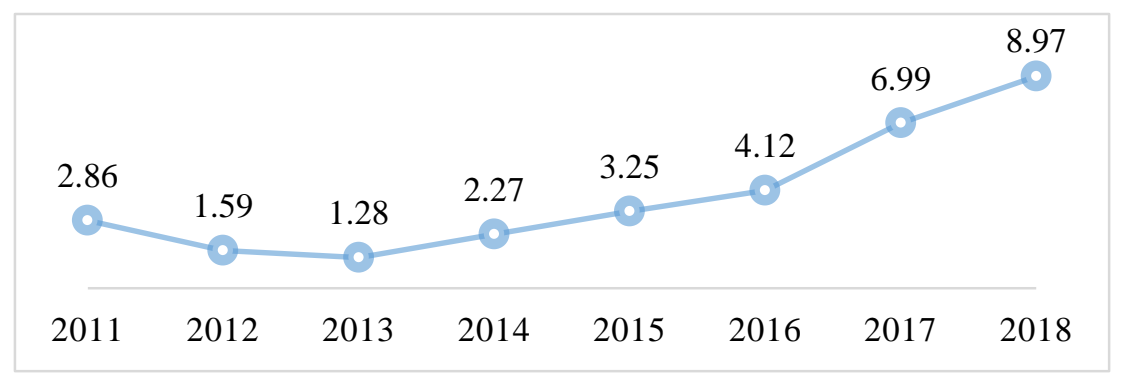

Figure 10. Case fatality rate according to year.

\section{Discussion}

In the last two decades, CDI has recurred as an infectious disease with increasing importance worldwide. The increase in the incidence of CDI, as well as an increasingly vulnerable population from the point of view of healthcare, has resulted in an increase in the frequency of medical and surgical complications, the appearance of additional health care costs but also increased mortality. Moreover, $\mathrm{CDI}$ is one of the more common pathologies that occur in patients previously considered to have a low risk of acquiring the disease [26]. Previous epidemiological studies have shown that CDI incidence varies between hospitals [27].

As a particular case, in the hospital included in this research, during the 8 years of study, about $20 \%$ of the AE were represented by the CDI. A significant increase in the incidence is observed in the first 5 years (from $7.8 \%$ in 2011 to $41.45 \%$ in 2016), almost every second patient who requested medical care for the diarrheal syndrome during that period being diagnosed with CDI. The spread was worrying in this department, which led to isolation measures and a judicious use of antibiotics, decreasing the prevalence slightly over the next 2 years though it remained at alarming levels. The average incidence rate during the study period was 2.76 cases per 10,000 patient-days with the largest variation in 2016 (3.80 cases per 10,000 patient-days) when the incidence rate was significantly increased both compared to the study average and to the incidence of 2.4 cases per 10,000 patient-days reported by the European Centre for Disease Prevention and Control (ECDC) in a 2016 study of 7711 cases in 20 European countries but in which Romania was not included [28].

Balsells et al. claimed a CDI rate of 3.54 per 10,000 patient-days/y in a meta-analysis in 229 publications between 2005-2015 using data from 41 countries (including Romania) [7]. In 2014, the incidence found in our research (2.08 cases per 10,000 patient) was lower than the 5.2 cases per 10,000 patient-days found by Popescu et al. (in a survey conducted on 393 patients from nine Romanian hospitals) but near the value of 2.86 cases per 10,000 patient-days reported by the same study for Timisoara County (a region near Oradea) [29]. The value we obtained, though identical to that at the European level, was lower than that reported by other Romanian studies, possibly since we excluded from the study the patients with $A A D$ who had negative $C D$ toxins according to our method of identification.

Male patients predominated in the CDI rate with a majority of $53.25 \%$, but this was not significantly notable. The highest rates of CDI were found in the 75-84-year-old group. According to ECDC surveillance from 2016, CDI is predominant in older patients, the median age being 75 [28]. Elderly patients have multiple comorbidities that require long-term medical care. Their immune systems are deficient, and most of their viral infections can develop into bacterial supra-infection, requiring antibiotic treatment [30].

Today, rural Romania remains deprived of fast and efficient access to healthcare, though services should have improved. CDI can have a delayed onset of up to 3 months following antibiotic treatment or discharge from the hospital, though this is often unknown to doctors who do not frequently treat this type of infection. Moreover, access to doctors in rural areas may be difficult, which is why the disease's infectious period may be prolonged, with patients becoming a source of infection in the community. CD spores spread through the environment, being found in soil, water, and in both human 
and animal intestinal tract. New medical studies have raised suspicions that CDI may be a zoonotic disease [31,32]. Contact with an environment contaminated by animal feces is more frequent in a rural area, and any delay in medical attention may slowly increase the risk of CDI incidence in the area.

The global consumption of antibiotics registered an increase of $65 \%$ in the period 2000-2015, Romania being classified in 2015 among the first four countries in the world, with the highest rates of antibiotic consumption [33], and the second among European countries [10]. The increase in antibiotic consumption up to 2015 reported by Romania coincided with an increase in CDI incidence during 2015-2016 secondary to antibiotic treatments. In the present study, the number of cases secondary to antibiotic use was significantly higher than those of patients treated with drugs from other groups at risk of CDI. The result we obtained is in agreement with the antibiotic consumption trend reported in Romania, for the monitored period [10].

Even if antibiotic treatment is one of the most important factors in the aetiology of CDI, different groups of antibiotics present different risks. In our study, cephalosporins were found to be more frequently associated with CDI (43\%), followed by fluoroquinolones (22\%). According to the literature, these two are classified as the highest risk group for CDI [34-36]. Awareness of the risk of introducing CDI within the medical staff has probably been a factor leading to the gradual replacement of the two groups of antibiotics with others presenting a low or medium risk of CDI, though the data we obtained differ from those reported by the ECDC for Romania during the study period. According to the ECDC, beta-lactam penicillin was the most frequent antibiotic (range 45.3-49.9\%) used in Romania during the 2011-2018 period [37], followed by other beta-lactams (including cephalosporins, range 15.3-20.6\%), and quinolones (range 11.8-14\%). The difference can be explained by the fact that CDI is frequently healthcare-associated, and the use of antibiotics is correlated with antimicrobial resistance in the region [11,12]. Research studies strongly correlate antibiotic prescription with a high risk of CA-CDI as in C. difficile connected to healthcare $[38,39]$. There is urgent need of new antibiotics with different ways of action to inhibit the growth of multi-drug-resistant bacteria. Identifying the molecules able to influence the efflux process may represent a different approach, given that recent data showed the action of the efflux process over the total resistance in microbial strains and that inhibiting efflux pumps with adenosine triphospate-binding casette $(A B C)$ transporter inhibitors may intensify the effect of antibiotics that trigger them [40].

The presence of related pathologies increases the likelihood that patients will come into contact with healthcare services, which, in turn, exposes patients to a possible environment contaminated with microorganisms, usually multidrug resistance bacteria or fungus. Most of the time, hospitalized patients benefit from medication responsible for dysbiosis, creating a favorable environment for CDI. In our study, most frequently associated with patients suffering CDI were CVD, PD, and PSH. Although CVD is not correlated with CDI, and the literature does not currently present dysbiosis as a side effect of cardiovascular treatment, these patients with CVDs require regular medical visits and frequent hospitalization to treat complications.

CDI may result in a 100\% mortality rate in case of an Atlas score of 8 to 10 points or more [41]. Severe complications such as fulminant colitis, toxic megacolon, colonic perforation and decompensations of comorbidities may lead to death in patients with CDI. With a proportional mortality of $72 \%$ for deaths induced by CDI, reported to the total number of deaths by infectious digestive diseases, we confirmed the conclusion reported in the literature: CDI is a seriously lethal emerging pathogen and the leading cause of death due to infectious digestive diseases. The case fatality rate reported by the literature varied according to time and hospital location. We found a fatality rate of $4.1 \%$ for the study period. Hensgens et al. in a 2006-2009 study of 1366 patients from 13 Dutch hospitals, found a case fatality rate of $3.7 \%$ [42]. In a survey conducted by Hota et al. of 501 CDI patients admitted to three Canadian hospitals in the period 2007-2008, the case fatality rate varied from $16 \%$ to $35 \%$ [43].

The case fatality rate was observed to have tripled during the study period, our results being in agreement with those reported in the literature, thus supporting an increasing trend [43]. The number of CDIs has risen in recent years, and the increase in mortality attributable to that infection is an alarming 
factor for the medical world. Possible causes for this may be increased incidence due to hypervirulent strains responsible for severe infections, or the emergence of strains resistant to antibiotics in general and especially to those usually used to treat this infection [44,45]. In Romania, the prevalence of the hypervirulent ribotype NAP1/B1/027 is high. In a population study by Popescu et al. from November 2013 to February 2014, conducted on 393 CDI patients in hospitals from six different counties in Romania (excluding Bihor county), ribotype 027 had a prevalence of $82.6 \%$ [29]. We could not determine the incidence of this ribotype during the study period, because the polymerase chain reaction test for $C D$ toxin genes was performed only in negative cases for immunochromatography assay of the CD toxins.

Gender was not observed to be associated with death in CDI patients in the present study, but the literature has no unitary opinion on this relationship. In a study conducted by Smith et al. in 2006-2010 on 474,513 CDI patients in 980 US hospitals, the number of deaths was higher in female cases [46]. In a French study of 40 CDI patients in 2007-2011, male cases were found to be frequently associated with severe outcomes [47]. Death was also found to be more prevalent in males in a 2012-2013 study of 373 CDI patients suffering from this pathology secondary to PPI medication [48]. However, other studies have identified no relationship between gender and mortality [49].

In this study, patients with CDI whose mean age was $73.97 \pm 8.91$ years were more likely to have a fatal outcome. In a study conducted by Schousboe et al., on 167 cases of CDI, from the Canterbury District Health Board, Canterbury Region, New Zealand, the median age of death related to CDI was 73 years, though a higher mortality rate was found in the first 30 days [50]. Older age brings immunodeficiency, dysbiosis, and other debilitating diseases that can be decompensated by a potentially severe diarrheal infectious disease such as CDI. All studies conducted so far regarding this aspect of CDI reached a consensus [51,52]. Patients with CDI often come to the hospital within a few days of the onset of appearance of symptoms, after having been referred to other health services, CDI usually being ignored during this initial period. In the first days following hospitalization, the patient's condition is usually serious and the comorbidities, if any, are decompensated, with the risk of death simultaneously increasing.

Today, CDI is a major health concern, especially to healthcare services. Due to an increasing incidence of CDI (including those previously considered low risk), the need to identify at-risk patients, to keep total incidence under control and to characterize the molecular epidemiology of CD strains, urgent measures are required. Therefore, in Romania, it is mandatory for the public healthcare system to re-evaluate the legislative provisions in force on infectious diseases, to review the protocols on this subject, to update and optimize the programs that take into account CDI. Sustainable policies, which are based on the idea of progress, should be focused on health and encourage a fair and periodic assessment of the results achieved in the health field as part of the development of sustainable public health programs.

\section{Conclusions}

The results of this retrospective epidemiological study indicate that during the research, about $20 \%$ of the AE were represented by the CDI, with an incidence of 2.76 cases per 10,000 patient days. A growing trend in annual incidence is observed in the first 5 years, which determined isolation measures and the judicious use of antibiotics and led to a slight decrease in the incidence in the next two years. Thus, this research revealed an increasing incidence of CDI in western Romania during 2011-2018, requiring urgent attention on excessive antibiotic consumption (Romania being the main European consumer, according to statistics). In addition, CD is an anaerobic spore-forming obligate bacterium, resistant to common antibiotics and with a severe clinical picture, capable of inducing death. This infection can be prevented only through collaboration between specialists, by implementing a national antibiotic administration program and through strict rules regarding hygiene and isolation.

Author Contributions: All authors contributed equally to this paper. Conceptualization, N.N., D.M.T. and S.B.; Data curation, D.C.N.-C., C.P. and O.M.; Formal analysis, N.N., D.C.N.-C., S.A.K., S.A. and M.R.; Investigation, C.P., T.A.M., O.M., S.A. and M.R.; Methodology, S.A. and M.R.; Software, N.N., T.A.M., and A.R.; Supervision, 
L.A. and S.B.; Validation, D.C.N.-C. and A.R.; Visualization, C.P.; Writing-original draft, N.N., S.A.K., D.M.T., L.A. and S.B.; Writing-review \& editing, D.M.T., S.B., A.R. All authors have read and agreed to the published version of the manuscript.

Funding: This research received no external funding.

Acknowledgments: The authors thank the University of Oradea for the support in publishing this paper.

Conflicts of Interest: The authors declare no conflict of interest.

\section{References}

1. Rodriguez-Palacios, A.; Borgmann, S.; Kline, T.R.; LeJeune, J.T. Clostridium difficile in foods and animals: History and measures to reduce exposure. Anim. Health Res. Rev. 2013, 14, 11-29. [CrossRef] [PubMed]

2. McDonald, L.C.; Owings, M.; Jernigan, D.B. Clostridium difficile infection in patients discharged from US short-stay hospitals, 1996-2003. Emerg. Infect. Dis. 2006, 12, 409-415. [CrossRef] [PubMed]

3. Bartlett, J.G.; Gerding, D.N. Clinical recognition and diagnosis of Clostridium difficile infection. Clin. Infect. Dis. 2008, 46, S12-S18. [CrossRef] [PubMed]

4. Haque, M.; Sartelli, M.; McKimm, J.; Abu Bakar, M. Health care-associated infections-An overview. Infect. Drug Resist. 2018, 11, 2321-2333. [CrossRef]

5. Chai, J.; Lee, C.H. Management of Primary and Recurrent Clostridium difficile Infection: An Update. Antibiotics 2018, 7, 54. [CrossRef] [PubMed]

6. Collins, D.A.; Riley, T.V. Clostridium difficile in Asia: Opportunities for One Health Management. Trop. Med. Infect. Dis. 2019, 4, 7. [CrossRef]

7. Barker, A.K.; Alagoz, O.; Safdar, N.; Barker, A.K.; Alagoz, O.; Safdar, N. Interventions to Reduce the Incidence of Hospital-Onset Clostridium difficile Infection: An Agent-Based Modeling Approach to Evaluate Clinical Effectiveness in Adult Acute Care Hospitals. Clin. Infect. Dis. 2018, 66, 1192-1203. [CrossRef]

8. Raviglione, M.; Maher, D. Ending infectious diseases in the era of the Sustainable Development Goals. Porto Biomed. J. 2017, 2, 140-142. [CrossRef]

9. Balsells, E.; Shi, T.; Leese, C.; Lyell, I.; Burrows, J.; Wiuff, C.; Campbell, H.; Kyaw, M.H.; Nair, H. Global burden of Clostridium difficile infections: A systematic review and meta-analysis. J. Glob. Health. 2019, 9, 010407. [CrossRef]

10. European Centre for Disease Prevention and Control. Consumption of Antibacterials for Systemic Use (ATC Group J01) in the Community (Primary Care Sector) in Europe, Reporting Year 2018. 2018. Available online: https:/www.ecdc.europa.eu/en/antimicrobial-consumption/database/rates-country/ (accessed on 18 November 2019).

11. Zaha, D.C.; Bungau, S.; Aleya, S.; Tit, D.M.; Vesa, C.M.; Popa, A.R.; Pantis, C.; Maghiar, O.A.; Bratu, O.G.; Furau, C.; et al. What antibiotics for what pathogens? The sensitivity spectrum of isolated strains in an intensive care unit. Sci. Total Environ. 2019, 687, 118-127. [CrossRef]

12. Zaha, D.C.; Bungau, S.; Uivarosan, D.; Tit, D.M.; Maghiar, T.A.; Maghiar, O.; Pantis, C.; Fratila, O.; Rus, M.; Vesa, C.M. Antibiotic consumption and microbiological epidemiology in surgery departments: Results from a single study center. Antibiotics 2020, 9, 81. [CrossRef]

13. Langdon, A.; Crook, N.; Dantas, G. The effects of antibiotics on the microbiome throughout development and alternative approaches for therapeutic modulation. Genome Med. 2016, 8, 39. [CrossRef]

14. Natarajan, M.; Walk, S.T.; Young, V.B.; Aronoff, D.M. A clinical and epidemiological review of non-toxigenic Clostridium difficile. Anaerobe 2013, 22. [CrossRef]

15. Di Bella, S.; Ascenzi, P.; Siarakas, S.; Petrosillo, N.; di Masi, A. Clostridium difficile Toxins A and B: Insights into Pathogenic Properties and Extraintestinal Effects. Toxins 2016, 8, 134. [CrossRef]

16. Leffler, D.A.; Lamont, J.T. Clostridium difficile infection. N. Engl. J. Med. 2015, 372, 1539-1548. [CrossRef]

17. Marra, A.R.; Perencevich, E.N.; Nelson, R.E.; Samore, M.; Khader, K.; Chiang, H.-Y.; Chorazy, M.L.; Herwaldt, L.A.; Diekema, D.J.; Kuxhausen, M.F.; et al. Incidence and Outcomes Associated with Clostridium difficile Infections: A Systematic Review and Meta-analysis. JAMA Netw. Open 2020, 3, e1917597. [CrossRef] 
18. Cohen, S.H.; Gerding, D.N.; Johnson, S.; Kelly, C.P.; Loo, V.G.; McDonald, L.C.; Pepin, J.; Wilcox, M.H. Clinical practice guidelines for Clostridium difficile infection in adults: 2010 update by the society for healthcare epidemiology of America (SHEA) and the infectious diseases society of America (IDSA). Infect. Control. Hosp. Epidemiol. 2010, 31, 431-455. [CrossRef]

19. Sava, C.N.; Ritli, L.; Balmos, A.B.; Iuhas, A.R.; Marian, P.; Motorca, M.A.; Lele, L.A.; Straciuc, O.; Zaha, D.C.; Jurcă, M.C.; et al. Unusual extramedullary relapses in a case of common B-cell acute lymphoblastic leukemia. Case report and review of literature. Rom. J. Morphol. Embryol. 2019, 60, 249-254.

20. Nale, J.Y.; Redgwell, T.A.; Millard, A.; Clokie, M.R.J. Efficacy of an Optimised Bacteriophage Cocktail to Clear Clostridium difficile in a Batch Fermentation Model. Antibiotics 2018, 7, 13. [CrossRef]

21. Crobach, M.J.T.; Vernon, J.J.; Loo, V.G.; Kong, L.Y.; Péchiné, S.; Wilcox, M.H.; Kuijper, E.J. Understanding Clostridium difficile colonization. Clin. Microbiol. Rev. 2018, 31, e00021-17. [CrossRef]

22. National Institute of Statistics, 2019. Anuarul Statistic al Judetului Bihor. (In English: Statistical Yearbook of Bihor County). Available online: https://www.bihor.insse.ro/wp-content/uploads/2019/03/Anuar2018.pdf (accessed on 24 February 2020).

23. Krutova, M.; Kinross, P.; Barbut, F.; Hajdu, A.; Wilcox, M.H.; Kuijper, E.J.; Survey Contributors. How to: Surveillance of Clostridium difficile infections. Clin. Microbiol. Infect. 2018, 24, 469-475. [CrossRef]

24. CERTEST Clostridium Difficilegdh+ Toxin A+B. Available online: https://www.certest.es/wp-content/ uploads/2020/05/IU-GX87V-v.01.pdf (accessed on 14 May 2020).

25. Xpert ${ }^{\circledR}$ C. difficile BT. Available online: https://www.cepheid.com/en/tests/Healthcare-Associated-Infections/ Xpert-C.-difficile-BT (accessed on 14 May 2020).

26. Depestel, D.D.; Aronoff, D.M. Epidemiology of Clostridium difficile infection. J. Pharm. Pract. 2013, 26, 464-475. [CrossRef]

27. Bauer, M.P.; Notermans, D.W.; van Benthem, B.H.; Brazier, J.S.; Wilcox, M.H.; Rupnik, M.; Monnet, D.L.; Dissel, J.T.; Kuijper, E.J.; ECDIS Study Group. Clostridium difficile infection in Europe: A hospital-based survey. Lancet 2011, 377, 63-73. [CrossRef]

28. ECDC (European Centre for Disease Prevention and Control). Clostridium Difficile Infections-Annual Epidemiological Report for 2016. 2018. Available online: https://www.ecdc.europa.eu/en/publications-data/ healthcare-associated-infections-clostridium-difficile-infections-annual/ (accessed on 18 November 2019).

29. Popescu, G.A.; Serban, R.; Pistol, A.; Niculcea, A.; Preda, A.; Lemeni, D.; Macovei, S.I.; Talapan, D.; Rafila, A.; Florea, D. The Recent emergence of Clostridium difficile infection in Romanian hospitals is associated with a high prevalence of polymerase chain reaction ribotype 027. Balk. Med. J. 2018, 35, 191-195. [CrossRef]

30. Asempa, T.E.; Nicolau, D.P. Clostridium difficile infection in the elderly: An update on management. Clin. Interv. Aging 2017, 12, 1799-1809. [CrossRef]

31. Knetsch, C.W.; Kumar, N.; Forster, S.C.; Connor, T.R.; Browne, H.P.; Harmanus, C.; Sanders, I.M.; Harris, S.R.; Turner, L.; Morris, T.; et al. Zoonotic transfer of Clostridium difficile harboring antimicrobial resistance between farm animals and humans. J. Clin. Microbiol. 2018, 56, e01384-17. [CrossRef]

32. Rodriguez, C.; Taminiau, B.; Van Broeck, J.; Delmee, M.; Daube, G. Clostridium difficile in Food and Animals: A comprehensive review. Adv. Exp. Med. Biol. 2016, 932, 65-92.

33. Klein, E.Y.; Van Boeckel, T.P.; Martinez, E.M.; Pant, S.; Gandra, S.; Levin, S.A.; Goossens, H.; Laxminarayan, R. Global increase and geographic convergence in antibiotic consumption between 2000 and 2015. Proc. Natl. Acad. Sci. USA 2018, 115, E3463-E3470. [CrossRef]

34. Brown, K.A.; Khanafer, N.; Daneman, N.; Fisman, D.N. Meta-analysis of antibiotics and the risk of community-associated Clostridium difficile infection. Antimicrob. Agents Chemother. 2013, 57, $2326-2332$. [CrossRef]

35. Deshpande, A.; Pasupuleti, V.; Thota, P.; Pant, C.; Rolston, D.D.; Sferra, T.J.; Hernandez, A.V.; Donskey, C.J. Community-associated Clostridium difficile infection and antibiotics: A meta-analysis. J. Antimicrob. Chemother. 2013, 68, 1951-1961. [CrossRef]

36. Vardakas, K.Z.; Trigkidis, K.K.; Boukouvala, E.; Falagas, M.E. Clostridium difficile infection following systemic antibiotic administration in randomised controlled trials: A systematic review and meta-analysis. Int. J. Antimicrob. Agents 2016, 48, 1-10. [CrossRef] [PubMed]

37. European Centre for Disease Prevention and Control. Distribution of Antimicrobial Consumption by Antimicrobial Group. 2019. Available online: https://www.ecdc.europa.eu/en/antimicrobial-consumption/ database/distribution-by-antimicrobial-group/ (accessed on 20 November 2019). 
38. Chiang, S.-R.; Lai, C.-C.; Ho, C.-H.; Chen, C.-M.; Chao, C.-M.; Wang, J.-J.; Cheng, K.-C. Prolonged Mechanical Ventilation Assistance Interacts Synergistically with Carbapenem for Clostridium difficile Infection in Critically Ill Patients. J. Clin. Med. 2018, 7, 224. [CrossRef]

39. Turner, N.A.; Smith, B.A.; Lewis, S.S. Novel and emerging sources of Clostridioides difficile infection. PLoS Pathog. 2019, 15, e1008125. [CrossRef]

40. Usai, D.; Donadu, M.; Bua, A.; Molicotti, P.; Zanetti, S.; Piras, S.; Corona, P.; Ibba, R.; Carta, A. Enhancement of antimicrobial activity of pump inhibitors associating drugs. J. Infect. Dev. Ctries. 2019, 13, 162-164. [CrossRef]

41. Hernandez-Garcia, R.; Garza-Gonzalez, E.; Miller, M.; Arteaga-Muller, G.; Galvan-de los Santos, A.M.; Camacho-Ortiz, A. Application of the ATLAS score for evaluating the severity of Clostridium difficile infection in teaching hospitals in Mexico. Braz. J. Infect. Dis. 2015, 19, 399-402. [CrossRef]

42. Hensgens, M.P.M.; Goorhuis, A.; Dekkers, O.M.; van Benthem, B.H.B.; Kuijper, E.J. All-cause and disease-specific mortality in hospitalized patients with Clostridium difficile infection: A multicenter cohort study. Clin. Infect. Dis. 2013, 56, 1108-1116. [CrossRef]

43. Hota, S.S.; Achonu, C.; Crowcroft, N.S.; Harvey, B.J.; Lauwers, A.; Gardam, M.A. Determining mortality rates attributable to Clostridium difficile infection. Emerg. Infect. Dis. 2012, 18, 305-307. [CrossRef]

44. Fatima, R.; Aziz, M. The hypervirulent strain of Clostridium difficile: NAP1/B1/027-A brief overview. Cureus 2019, 11, e3977. [CrossRef]

45. Banawas, S.S. Clostridium difficile Infections: A global overview of drug sensitivity and resistance mechanisms. BioMed Res. Int. 2018, 2015, 9. [CrossRef]

46. Smith, A.M.; Wuerth, B.A.; Wiemken, T.L.; Arnold, F.W. Prevalence of Clostridium difficile infection presenting to US EDs. Am. J. Emerg. Med. 2015, 33, 238-243. [CrossRef]

47. Khanafer, N.; Toure, A.; Chambrier, C.; Cour, M.; Reverdy, M.E.; Argaud, L.; Vanhems, P. Predictors of Clostridium difficile infection severity in patients hospitalised in medical intensive care. World J. Gastroenterol. 2013, 19, 8034-8041. [CrossRef] [PubMed]

48. Dos Santos-Schaller, O.; Boisset, S.; Seigneurin, A.; Epaulard, O. Recurrence and death after Clostridium difficile infection: Gender-dependant influence of proton pump inhibitor therapy. Springerplus 2016, 5, 430. [CrossRef] [PubMed]

49. Boone, J.H.; Goodykoontz, M.; Rhodes, S.J.; Price, K.; Smith, J.; Gearhart, K.N.; Carman, R.J.; Kerkering, T.M.; Wilkins, T.D.; Lyerly, D.M. Clostridium difficile prevalence rates in a large healthcare system stratified according to patient population, age, gender, and specimen consistency. Eur. J. Clin. Microbiol. Infect. Dis. 2012, 31, 1551-1559. [CrossRef] [PubMed]

50. Schousboe, M.; Barrett, R.; Wildbore, A.M. Clostridium difficile-related 30-day mortality: A case-control study. Infect. Dis. Clin. Pract. 2013, 21, 366-372. [CrossRef]

51. Karas, J.A.; Bradshaw, S.; Mahmud, W.; Enoch, D.A. Mortality in hospitalized older adults associated with Clostridium difficile infection at a district hospital. Infect. Dis. Rep. 2010, 2, e8. [CrossRef]

52. Pechal, A.; Lin, K.; Allen, S.; Reveles, K. National age group trends in Clostridium difficile infection incidence and health outcomes in United States community hospitals. BMC Infect. Dis. 2016, 16, 682. [CrossRef]

(C) 2020 by the authors. Licensee MDPI, Basel, Switzerland. This article is an open access article distributed under the terms and conditions of the Creative Commons Attribution (CC BY) license (http://creativecommons.org/licenses/by/4.0/). 